\title{
gMOOCs - Flow and Persuasion to Gamify MOOCs
}

Citation for published version (APA):

Antonaci, A., Peter, D., Klemke, R., Bruysten, T., Stracke, C. M., \& Specht, M. (2017). gMOOCs - Flow and Persuasion to Gamify MOOCs. In J. Dias, P. A. Santos, \& R. C. Veltkamp (Eds.), Games and Learning Alliance: 6th International Conference, GALA 2017, Lisbon, Portugal, December 5-7, 2017, Proceedings (pp. 126-136). Springer. Lecture Notes in Computer Science Vol. 10653 https://doi.org/10.1007/978-3-319-71940-5_12

DOI:

10.1007/978-3-319-71940-5_12

Document status and date:

Published: 01/11/2017

Document Version:

Peer reviewed version

\section{Document license:}

CC BY-NC-ND

Please check the document version of this publication:

- A submitted manuscript is the version of the article upon submission and before peer-review. There can be important differences between the submitted version and the official published version of record. People interested in the research are advised to contact the author for the final version of the publication, or visit the DOI to the publisher's website.

- The final author version and the galley proof are versions of the publication after peer review.

- The final published version features the final layout of the paper including the volume, issue and page numbers.

Link to publication

\section{General rights}

Copyright and moral rights for the publications made accessible in the public portal are retained by the authors and/or other copyright owners and it is a condition of accessing publications that users recognise and abide by the legal requirements associated with these rights.

- Users may download and print one copy of any publication from the public portal for the purpose of private study or research.

- You may not further distribute the material or use it for any profit-making activity or commercial gain

- You may freely distribute the URL identifying the publication in the public portal.

If the publication is distributed under the terms of Article 25fa of the Dutch Copyright Act, indicated by the "Taverne" license above, please follow below link for the End User Agreement:

https://www.ou.nl/taverne-agreement

Take down policy

If you believe that this document breaches copyright please contact us at:

pure-support@ou.nl

providing details and we will investigate your claim.

Downloaded from https://research.ou.nl/ on date: 26 Apr. 2023 
Antonaci A., Peter D., Klemke R., Bruysten T., Stracke C.M., Specht M. (2017) gMOOCs - Flow and Persuasion to Gamify MOOCs. In: Dias J., Santos P., Veltkamp R. (Eds) Proceedings of Games and Learning Alliance Conference. GALA 2017. Lecture Notes in Computer Science, vol 10653. Springer, Cham

https://doi.org/10.1007/978-3-319-71940-5_12

\title{
gMOOCs - Flow and Persuasion to Gamify MOOCs
}

\author{
Alessandra Antonaci ${ }^{1}$, Daria Peter ${ }^{2}$, Roland Klemke ${ }^{1,2}$, Tim Bruysten ${ }^{2}$, Christian M. $^{2}$ \\ Stracke $^{1}$, Marcus Specht ${ }^{1}$ \\ ${ }^{1}$ Welten Institute, Open University of the Netherlands, Heerlen, Netherlands \\ ${ }^{2}$ Mediadesign Hochschule, Faculty of Gamedesign, Düsseldorf, Germany \\ \{Alessandra.Antonaci, Roland.Klemke, Christian.Stracke, Marcus.Specht\}@ou.nl, \\ daria.peter93@googlemail.com, T.Bruysten@mediadesign.de
}

\begin{abstract}
Gamification has gained great interest recently in several fields. However, while the literature reports that a gamification design relying on external motivation only can lead users to cognitive dissonance, most gamification approaches use points, badges and leaderboards as dominant game elements. We present our developed testable predictions with the aim of investigating additional motivational theories (flow and persuasion) to argue for a deeper integration of gamification and the learning content at hand. Relying on expert selected game elements, we consequently derive design considerations to create gMOOCs, gamified massive online open courses, designed according to the principles of flow and persuasion. Our findings are the basis of our experiment and a contribution to the development of a new theoretical design for gamification.
\end{abstract}

Keywords. Gamification, Flow, Persuasion, Design, Game Elements, MOOC

\section{Introduction}

Gamification in recent years has gained the attention of scholars, researchers and experts from several sectors [1] with its overall aim of helping and fostering behavioural change towards a variety of goals (e.g. better performance, better goal achievement, higher motivation and higher engagement). Gamification is influenced by several disciplines, such as: game design, psychology, instructional design and didactics. This multidisciplinary nature makes its design complex [2]. If gamification is to go beyond merely appealing visualisations, its design implies a deep knowledge and understanding of the context application scenario, the problem/s to be solved, the end users' characteristics (on individual and social connection levels) and of course of game design, in particular the game elements to be transferred.

In our application scenario, Massive Online Open Courses (MOOCs), the problems to be solved comprise a lack of personalisation to reach individual's goals, and a lack of sense of community among MOOC users, both possible causes of high dropout rates, a phenomenon well-known in these environments. [3]. Today, the game elements most commonly found in implemented gamification solutions are points, badges and leaderboards (known as PBL), which are rewards given to participants 
who mainly derive their motivational character from social comparison theory $[4,5]$. Aiming at generating behaviour change in our target population in order to improve engagement and sense of community, we investigate two further theories: the Flow Theory [6], connected more with engagement at the individual level and the Theory of Persuasion [7, 8], that looks at decision making under social influence in work situations and online communities.

To design a gamification framework, it is fundamental to know and understand how game elements can be inserted in non-gaming contexts. In previous work we thus conducted several studies to select appropriate game elements: we analysed the literature and game element collections such as [9], we involved experts in game design, learning science, and technology-enhanced learning, to assess our first selection of game elements $[2,10]$ and identified nine game elements rated according to their expected potential to enhance learning performance, goal achievement, and engagement within MOOCs. These elements are: (g1) empowerment, (g2) smooth learning curves, (g3) communication channels, (g4) levels, (g5) clues, (g6) goal indicators, (g7) skills tree, (g8) guilds, and (g9) storytelling.

To develop testable predictions, these game elements are better explained and linked to the theories mentioned above to highlight (1) their potential to create or support immersive learning experiences based on flow theory and enhance engagement [11] and (2) their potential to influence learner behaviour based on theories of persuasion $[7,8]$ and enhance the sense of community.

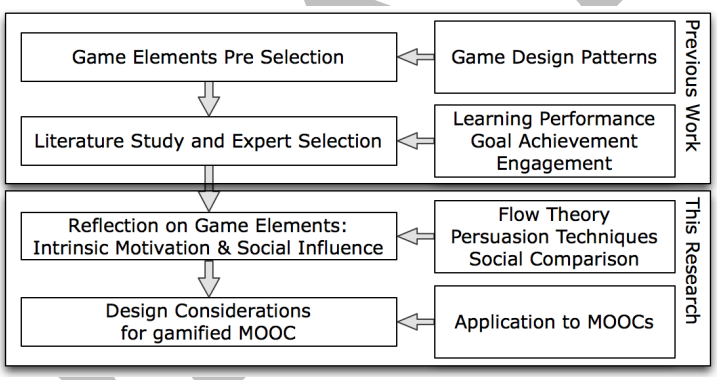

Fig. 1. Research steps towards gamification of MOOCs (gMOOC)

The paper is organised as follows: first the theories of flow and persuasion, are detailed, second a concept of gamification in MOOC (gMOOC) based on these theories is presented. We conclude with our design considerations and future work.

\section{Theories of Flow and Persuasion}

We refer to these two theories in particular because they allow us to understand how an individual could be engaged in an activity (flow) as well as how the social component can play a role in making choices (persuasion).

According to Csíkszentmihályi, flow is "a state of joy, creativity and total involvement, in which problems seem to disappear and there is an exhilarating feeling of transcendence" [12]. This "state" is achievable in types of activities that "have rules that require the learning of skills, they set up goals, they provide feedback, they 
make control possible. They facilitate concentration and involvement by making the activity as distinct as possible from the so-called "paramount reality" of everyday existence" [12]. Several players can witness to have reached this state.

Csíkszentmihályi also underlines how this pleasant state can be recreated by designing it, flow indeed has a specific set of conditions that have to be met for it to occur. These conditions require a balance of skills and challenges, clear goals, and unambiguous feedback [13] (Fig. 2). In particular, nine components putatively facilitate the flow experience and have to be considered for its design: (f1) clear goals; (f2) focus and concentration; (f3) loss of the feeling of self-consciousness; (f4) distorted perception of time; (f5) immediate feedback; (f6) balance between challenge and skill; (f7) sense of control; (f8) intrinsically rewarding character of activity; and (f9) merging of action and awareness [14]. Here below they are better described:

(f1) Clear goals. In order for users to get involved in an activity, access to procedural information is needed. Goals facilitate order in consciousness, i.e. they provide a spectrum for action, set expectations, and focus on users' intentions [15].

(f2) Focus and concentration. The execution of a task or skill requires a certain amount of conscious focus [14]. Activities like sports that require a fast shift of attention, and therefore focus, demand a constant evaluation of the situation at hand that is accompanied by periods of low and high focus.

(f3) Loss offeeling of self-consciousness. When a person is in the flow "there is no room for self-scrutiny. Because enjoyable activities have clear goals, stable rules, and challenges well matched to skills, there is little opportunity for the self to be threatened" [11].

(f4) Distorted sense of time. The alteration of time is experienced as either increasing in speed or slowing down [11].

(f5) Immediate feedback. Since flow is a dynamic state of mind, during which a constant improvement of skills takes place, transparency of performance parameters and their adjustment to skills acquired is crucial [11]. If the information on performance is ambiguous or only available when no longer relevant, it may lead to a mental state described as cognitive dissonance [16].

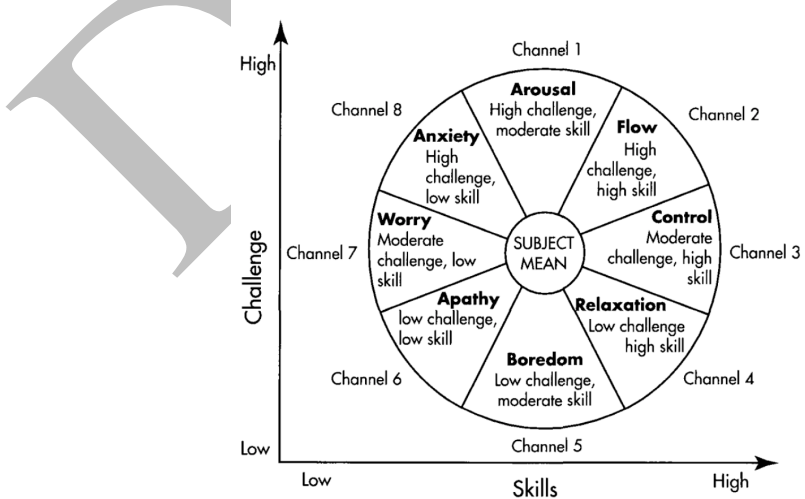

Fig. 2. "A model for the analysis of experience. Perceived challenge is on the ordinate, and perceived skill is on the abscissa"[17].

(f6) Balance between challenge and skills. This is the most notable dimension of flow that is essential for flow to emerge during an activity. Here, "challenge" is 
perceived as any opportunity an individual can respond to, and "skill" as the capability of responding to it accordingly, with the ability to actively influence possible outcomes in one's favour [14]. Figure 2 illustrates the 8-channel flow model.

"The original model assumed that enjoyment would occur along the entire diagonal, that is, when challenges and skills were both very low, as well as when they were both very high. Empirical research findings later led to a modification of the model. People did not enjoy situations in which their skills and the outside challenges were both lower than their accustomed levels. The new model predicts flow only when challenges and skills are relatively in balance, and above the individual's mean level [...]" [11].

(f7) Sense of control. A strengthened sense of control might seem to contradict the loss of self-consciousness, however, it is described as a state of mind during which an individual has no awareness of control but is rather unconcerned about a possible lack of control [18]. Introspectively, the amount of control during flow is perceived as adequate, as an inappropriate amount of control could result in anxiety, thus disrupting flow [14]. In that context, individuals engage in activities that include a certain amount of risk or uncertainty not in the pursuit of thrill or excitement, but because they are competent in influencing the situation at hand.

(f8) Intrinsically rewarding. One of the major characterisations of the flow experience is that its rewards can be derived from the experience itself, making it autotelic. It represents a "psychological state, based on concrete feedback, which acts as a reward in that it produces continuing behaviour in the absence of other rewards" [18]. In that sense, intrinsic rewards contain the feelings of personal achievement and joy, being merits that are not primarily associated with material enrichment that strengthen long-term motivation. In contrast, if an activity is mainly providing external rewards like monetary items or objects of value, motivation to endorse oneself further in that particular activity is decreased [19], making voluntary engagements in that activity in the future less likely.

(f9) Merging of action and awareness. In a situation in which all of an individual's relevant skills are needed to comprehend challenges at hand, attention is completely utilised to cope with the activity [11]. Actions then appear to happen spontaneously and automatically, with consciousness immersed in the actions performed.

Continuing our explanation with the second theory: the theory of persuasion (influence) developed by Cialdini, sets out six principles, describing humans taking decisions under social influence [7]. In our life as well as in games and in MOOC environments people are invited to make choices. In investigating online interactions, even if the non-verbal clues are not recorded, "social category cues are still available and people may respond to influence appeals based on those cues" [8]. The theory of persuasion explains, based on the following six principles how human behaviour can be (ethically) guided in making decisions and underlines the importance of the social factor in communication [7]: (p1) commitment and consistency, (p2) reciprocity, ( $p 3)$ social proof (consensus), (p4) authority, (p5) liking, and (p6) scarcity. While originally intended for direct interpersonal interaction, we aim to analyse and adapt these principles to gamification as detailed below.

(p1) Commitment and consistency. This principle rests on the assumption that humans strive to avoid inconsistency in their behaviour in social situations, which is associated with indecisiveness, confusion and mental instability, whereas consistent 
behaviour is associated with intelligence, stability and honesty [7]. Consistent behaviour can be turned into automated behaviour, preceding reflective thinking.

In order for a tactic based on commitment to reach its full potential, an individual has to personally commit to a decision or an offer s/he has received [7]. In theory, a personal statement of agreement or a demonstration of compliance alters behaviour associated with the offer or subject at hand in a way that makes it a part of personal identity and therefore, something to defend or sustain.

(p2) Reciprocation. The general idea behind reciprocation is that after receiving help or a gift, whether asked for or not, our associations with it include an undesirable feeling of indebtedness and obligation which demands we give back what we received $[7,20]$.

(p3) Social proof. One method of coping with a situation at hand is by observing the behaviour of others and adjusting one's own accordingly [7]. Social proof provides information on what to do or on how to act based on a consensus, deducting that some behaviour is appropriate in a certain situation, when the surrounding social environment is displaying the named behaviour [21]. Additionally, the imitation of behaviour is more likely to occur when the model is someone well-perceived, attractive, relatable and familiar.

(p4) Authority. This principle underlines how much people rely on authority, e.g. they "are more likely to give change for a parking meter to a complete stranger if that requester wears a uniform rather than casual clothes" [22]. Applied to MOOC environments, this principle highlights the importance of credibility. Studying the effect of expertise involved in computer-mediated and face to face discussions in online communities, [8] reports that people are more likely to follow the point of view of the authority perceived as expert.

(p5) Liking. People are more willing to comply with a request from someone they like as examined in situations in which, e.g., one's own purchase of an item is based on the suggestion of a familiar, well-perceived person [7]. Additionally, the principle of liking incorporates a concept called the "halo effect" [23], that describes the emergence of a cognitive bias related to a person and objects or people directly associated with him or her, based on previous evaluations of that person.

(p6) Scarcity. The principle of scarcity refers to the idea that "potential loss plays a large role in human decision making" [7]. Opportunities, offers, or items, are pursued more frequently if they display a "potential unavailability". Consequently, the degree of scarcity of an item can be used as a rule of thumb to estimate its worth, without the need to analyse the item in detail.

\section{Gamification based on flow and persuasion}

The three dominant game elements used for gamification in education found in the literature are: points, badges and leaderboards (also known as PBL) [24]. A few examples of gamified MOOCs are also available in the literature [2]. From a design perspective using points, badges and leaderboards implies a focus on extrinsic motivation related to social comparison theory [4] [5]. While Cialdini's principles of persuasion seem to appeal to compliance and identification related to the social 
dimension, the flow theory allows us to reflect on gamification design from an individual point of view. Furthermore, Csíkszentmihályi’s flow theory represents a closed approach to behaviour alterations via intrinsically rewarding processes. We aim to use both theories in our comprehensive gamification framework reflecting on the potential to facilitate enjoyment and engagement in the learners by addressing extrinsic and intrinsic motivational aspects.

The starting point for this framework is the selection of the nine expert-selected game elements described earlier extended with the list of most commonly used elements (PBL). To reflect these game elements in the light of flow theory and persuasion techniques, we map them with the dimensions of flow and persuasion as described above. This mapping will lead us towards testable predictions on the effects of specific game elements on elements of flow and persuasion. Table 1 summarises the relations between game elements and flow theory/persuasion techniques, which are detailed below.

Table 1. Mapping game elements with dimensions of flow and persuasion

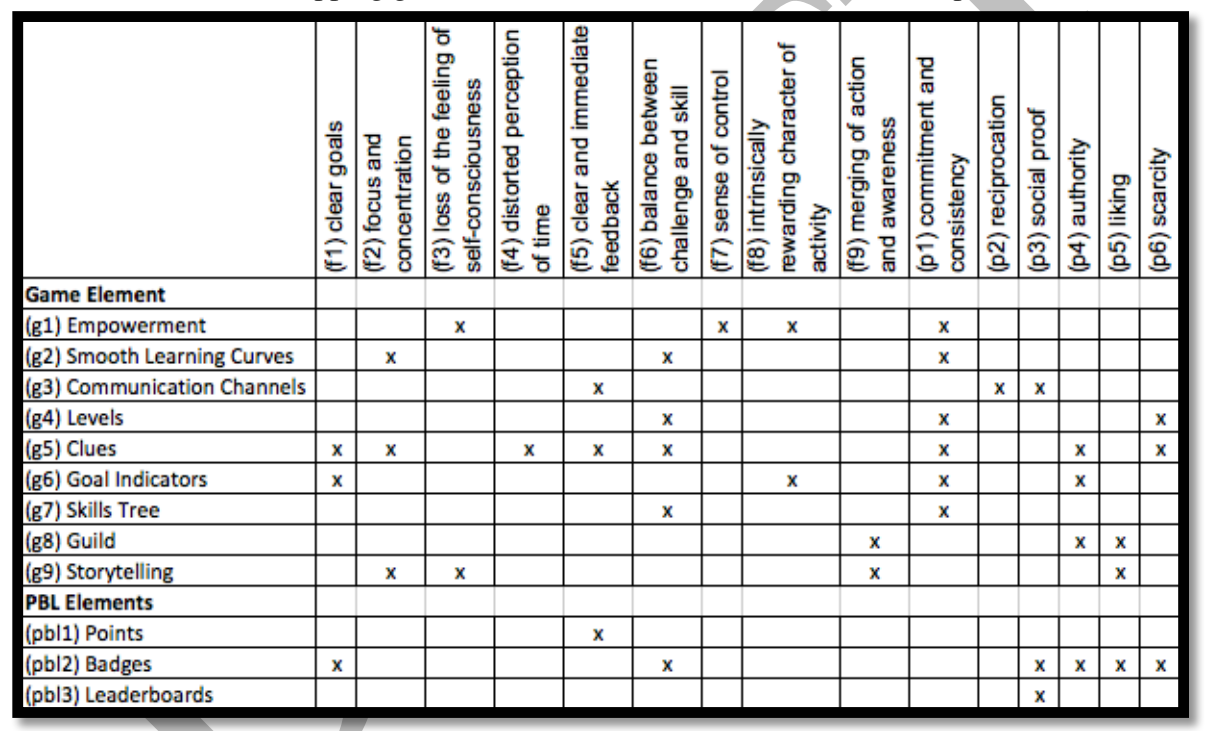

(g1) Empowerment ("Players feel that they can affect the events and the final outcome of a game"[9]) delivers a sense of control (f7) to learners. Empowerment also helps to foster the intrinsically rewarding character of actions (f8) by supporting self-efficacy, as well as being able to support the loss of feeling of self-consciousness (f3) by involving the user in the action itself. Commitment and consistency (p1) is supported since empowerment leads to individual decisions the learner commits to and to consistent action-response cycles.

(g2) Smooth Learning Curves (enable the chance to "smoothly progress from novice to master" [9]) help to gain focus and concentration (f2) as well as a balance between challenge and skills (f6), as they avoid overly complex or too simple learning situations. They also support commitment and consistency (p1) by designing the learning progress in a consistent way. 
(g3) Communication Channels ("the medium and the methods players can use to send messages to other players" [9]), enable clear and immediate feedback (f5) by peers and tutors, but also support reciprocation (p2) by allowing learners to communicate and exchange favours. Social proof (p3) can be supported by communication channels as well, since the behaviour of community members can be part of the communication.

(g4) Levels ("part of the game in which all players' actions take place until a certain goal has been reached or an end condition has been fulfilled" [9]) can be used to support a balance between challenge and skill (f6), since they complement the smooth learning curve with a game design approach to design increasing challenges. Levels also support consistency and commitment (p1), by representing closed, consistent environments, which the learner commits to finishing. The design of different levels can also provide scarcity (p6) by using various level elements in varying frequency.

(g5) Clues ("game elements that give the players information about how the goals of the game can be reached" [9] ) are a game element that can be used in a large variety of different ways. Consequently, clues can be used to indicate clear goals (f1), to help focus and concentration (f2) by directing the learner to relevant aspects, to help dissolve a distorted perception of time (f4) by pointing towards breaks or session ends, to give clear and immediate feedback (f5), and to support the balance between challenge and skills (f6), by guiding a lost learner towards solutions. Clues can also underline consistency ( 1 1) by directing the learner's attention or represent authority (p4) by giving direction. Clues should be realised using principles of scarcity (p6).

(g6) Goal Indicators (give information to players about their current goals in the game), help to indicate, set, and follow clear goals (f1). Goal indicators also support commitment (by fostering goal achievement) and consistency (by allowing for longterm oriented goals) (p1). When goal indicators are used to guide the learner, they can also represent authority (p4). Furthermore, the achievement of a specific goal can be intrinsically rewarding for the learner (f8).

(g7) Skill trees (enable custom configurations of a character's abilities, often organised in branches) support the design of balanced challenges and skills (f6) and as levels support consistency and commitment (p1).

(g8) Guilds ("associations of players who chose to come together to achieve a common goal" [25, 26]) can be used to streamline clear goals (f1) and foster communication and collaboration, which helps to support reciprocation (p2), social proof (p3), linking (p5), as well as authority (p4).

(g9) Storytelling ("the act of telling stories within the game"[9]) can be flexibly used for many contextualising or framing objectives. It offers opportunities to foster focus and concentration (p2) by providing an interesting story line. It can support the loss of feeling of self-consciousness (f3) by immersing the learner into the story. When storyline and user activities are well integrated, storytelling can support the merging of action and awareness (f9).

(pbl1) Points ("numerical representation of the player's success in the game"[9]) can be used to indicate immediate feedback (f5).

(pbl2) Badges (the act of telling stories within the game) can be flexibly used to support clear goals (f1) or indicate the balance between challenge and skills (f6). 
Badges can also utilise the principle of scarcity (p6) and enable liking (p5), authority (p4), and social proof (p3).

(pbl3) Leaderboards ("give players the chance to rank themselves against other players who have previously played the game" [9] or are playing it in parallel) underline the concept of social proof (p3).

\section{Application to MOOCs - design considerations}

Since the implementation of a specific game element is a creative process with many choices, we additionally derive design considerations, which should help to apply game elements in a way helpful to support flow and persuasion as desired. In this section, we thus reflect on the application of the previously introduced game elements in the context of MOOCs to find out how far they can help in reaching one or more of the following goals: (gol) improve community building, (go2) enhance goal achievement and (go3) engagement.

(g1) Empowerment. The sense of control given to the learner should be represented by the possibility of explicitly stating individual learning goals, which can be followed-up. This way, the learner can continuously assess his/her way towards achieving the stated goal. Empowerment can consequently contribute mainly to ( $g o 2)$, with possible side effects on (go3).

(g2) Smooth Learning Curves. Keep the learner in continuous learning progress and thus contribute to (go3). In the light of designing a MOOC, smooth learning curves need to be treated already at early stages of the design, since they need to be reflected in the way, the learning content is structured and organised.

(g3) Communication Channels. Engagement is often related to the sense of community ( $g o l)$. Communication channels are a key way to connect community members and thus contribute to (go3).

(g4) Levels help to foster smooth learning curves by creating varying difficulty, which consequently contributes to (go3). Furthermore, levels can be used to encapsulate specific learning goals in a closed environment: each level should be to some extent self-contained, which contributes to a higher level of individual goal achievement (go2).

(g5) Clues can be a design tool to help smoothen the learning curves and affect go2 and go3. Indeed, clues can be used to reflect on the individual progress towards goal achievement, by indicating e.g. a deviation from the goals originally set (go2).

(g6) Goal Indicators are clearly related to (go2) and should be used to monitor individually set learning goals and the learner's progress towards achieving them. If set up as a group activity, they can also affect community building ( $\mathrm{gol})$.

(g7) Skill trees can be a means to help specify individual learning goals (go2), e.g. representing required, gained, or targeted skills, probably having an effect on users' engagement ( $g$ o3).

(g8) Guilds directly support ( $g o l)$, by increasing the sense of community and fostering communication, they can impact on (go3). However, guilds and their strong social coherence can also be a hindrance to individual goal achievement ( $g o 2)$. 
(g9) Storytelling can positively impact (go3), by creating a motivating context for the learning content. However, storytelling can be problematic in designing selfcontained, individual learning units (as required for go2), since the ongoing nature of a story might be disturbed.

(pbl1) Points help to represent learning progress and success, and can be seen as external motivators towards (go2) and (go3).

(pbl2) Badges can be used as individual indicators for progress towards learning goals and thus support (go2). If combined with the scarcity criterion, they can foster (go3).

(pbl3) Leaderboards allow learners to compare themselves with other learners and can be expected to contribute to ( $\mathrm{go3}$ ).

Based on this reflection we can state that the game elements previously selected seem to be supported by both the theories presented in this paper. Further empirical investigations in the context of MOOC are needed.

\section{Conclusions}

While most of today's gamification approaches rely on game elements related to social comparison, we looked at game elements that are inherently more deeply integrated into the learning progress within MOOCs. Based on flow theory and principles of persuasion, we have reflected on a number of game elements to assess their potential contribution to raise individual motivation (flow) and social interaction (persuasion). We found that with these game elements additional dimensions of motivation beyond social comparison can be supported. Moving towards implementing selected game elements in MOOCs, we have further analysed the possible contribution of these game elements to reaching the described goals (go1go3) based on implementation intention theory. We found that, while all the different goals can be supported by some of the selected game elements, also conflicts between game elements can arise (e.g. Storytelling contributes to go2, but complicates go3).

As a conclusion, we can state, that more deeply integrating gamification with the learning content at hand can pave the way towards motivating and intriguing learning environments - gMOOCs, which potentially support individual motivation, social interaction, as well as social comparison to address the current shortcomings of MOOCs. Further research is required to empirically assess and measure effects on the goals described as triggered by the different game elements or combinations thereof.

\section{References}

1. Hoflinger, P.J., Zimmerling, E.: Monitoring Gamification in International Patent Documents: Technology Classes, Firms and Preliminary Value Indicators. In: 2016 49th Hawaii International Conference on System Sciences (HICSS). pp. 1319-1327. IEEE (2016)

2. Antonaci, A., Klemke, R., Stracke, C.M., Specht, M.: Gamification in MOOCs to enhance users' goal achievement. In: Proceedings of IEEE Global Engineering 
Education Conference (EDUCON 2017), 25-28 April, Athens Greece. IEEE Xplore (2017).

3. Cook, S., Bingham, T., Reid, S., Wang, L.: Going massive: Learner engagement in a MOOC environment. (2015).

4. Christy, K.R., Fox, J.: Leaderboards in a virtual classroom: A test of stereotype threat and social comparison explanations for women's math performance. Comput. Educ. 78, 66-77 (2014).

5. Mazarakis, A.: Using Gamification for Technology Enhanced Learning: The Case of Feedback Mechanisms. Bull. IEEE Tech. Comm. Learn. Technol. 17, 6-9 (2015).

6. Csikszentmihalyi, M.: Flow: The Classic Work on How to Achieve Happiness. Rider (2002).

7. Cialdini, R.B.: Influence : the psychology of persuasion. Harper Business (2007)

8. Guadagno, R., Cialdini, R.: Online persuasion and compliance: Social influence on the Internet and beyond. Soc. net Soc. Psychol. (2005).

9. Björk, S., Holopainen, J.: Patterns in Game Design. (2005)

10. Antonaci, A., Klemke, R., Stracke, C.M., Specht, M.: Identifying game elements suitable for MOOCs. In: Proceedins at the 12th European Conference on Technology Enhanced Learning. Springer Lecture Notes in Computer Science (LNCS) series., Tallinn (Estonia), 12 - 15 September 2017.

11. Csikszentmihalyi, M.: Flow : the psychology of optimal experience. HarperPerennial (1991).

12. Csikszentmihalyi, M.: Flow : the psychology of happiness. Rider (1992).

13. Csikszentmihalyi, M.: Finding flow: the psychology of engagement with everyday life. BasicBooks (1997).

14. Csikszentmihalyi, M., Csikszentmihalyi, I.S.: Optimal Experience: Psychological Studies of Flow in Consciousness, (1988).

15. Kock, F. De: The neuropsychological measure (EEG) of flow under conditions of peak performance, http://uir.unisa.ac.za/handle/10500/14359, (2014).

16. Festinger L.: A theory of cognitive dissonance. (1957).

17. Massimini, F., Carli, M.: The systematic assessment of flow in daily experience. In: Csikszentmihalyi, M. and Csikszentmihalyi, I.S. (eds.) Optimal experience: Psychological studies of flow in consciousness. pp. 266-287. Cambridge University Press, New York (1988).

18. Csikszentmihalyi, Mihaly: Beyond boredom and anxiety. Jossey-Bass (2000).

19. Deci, E.L.: Effects of externally mediated rewards on intrinsic motivation. J. Pers. Soc. Psychol. (1971).

20. Regan, D.T.: Effects of a favor and liking on compliance. J. Exp. Soc. Psychol. (1971).

21. Pratkanis, A.R.: The science of social influence: advances and future progress. Psychology Press (2007).

22. Influence at Work: Principles of Persuasion, https://www .influenceatwork.com/principles-of-persuasion/.

23. Nisbett, R., Wilson, T.: The halo effect: Evidence for unconscious alteration of judgments. J. Personal. Soc. (1977).

24. Silpasuwanchai, C., Ma, X., Shigemasu, H., Ren, X.: Developing a Comprehensive Engagement Framework of Gamification for Reflective Learning. In: Proceedings of the 2016 ACM Conference on Designing Interactive Systems - DIS '16. pp. 459-472. ACM Press, New York, New York, USA (2016).

25. Riegle, R., Matejka, W.: The learning guild: MMORPGs as educational environments. Distance Teach. Learn. .... (2006).

26. Knautz, K., Göretz, J., Wintermeyer, A.: \&quot;Gotta Catch 'Em All\&quot; - Game Design Patterns for Guild Quests in Higher Education. In: iConference. pp. 690-699 (2014). 


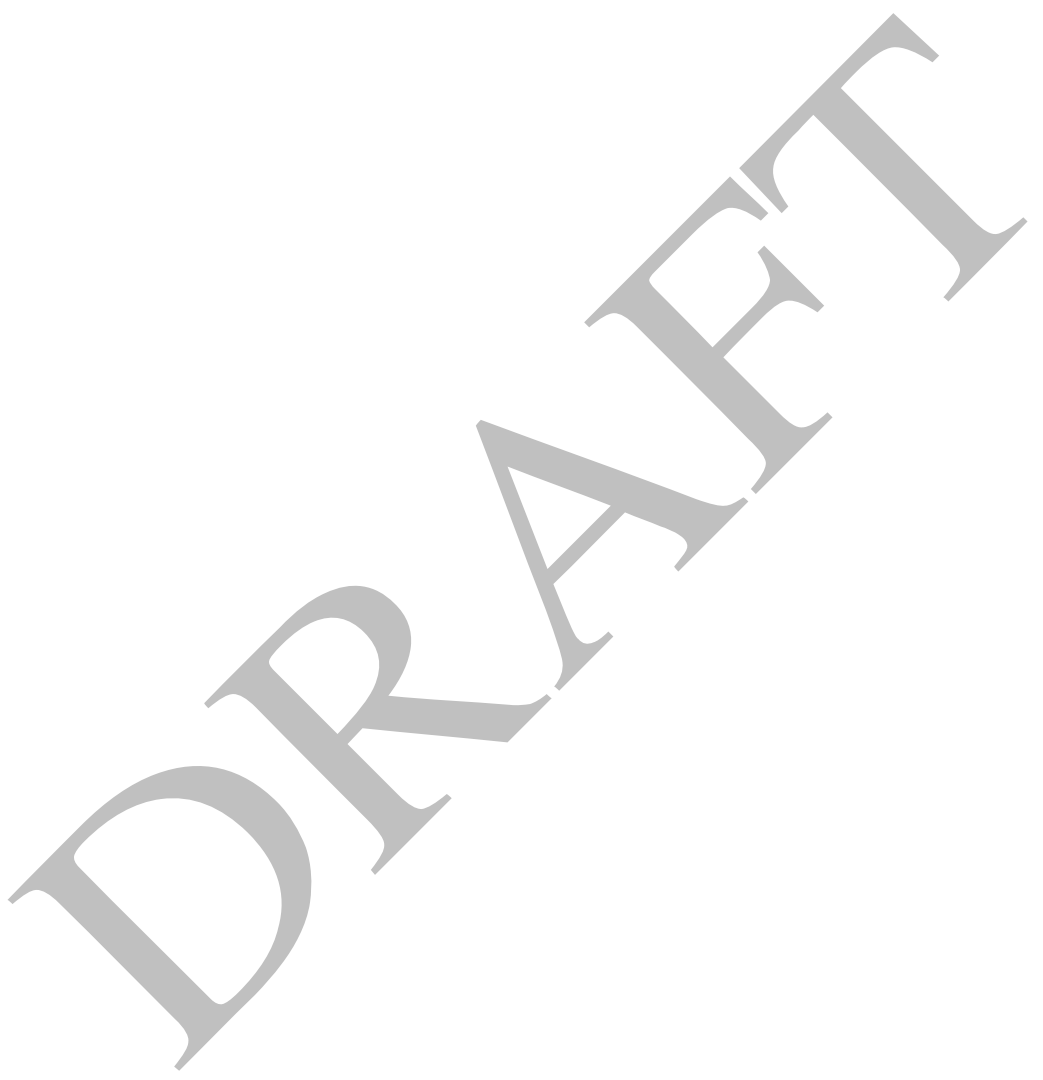

